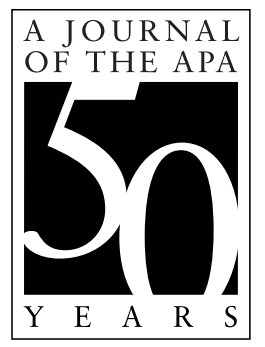

\title{
The Young AdULT CHRONIC PATIENT: A LOOK BACK
}

\author{
Francine Cournos, M.D. \\ Stephanie Le Melle, M.D.
}

Editor's Note: In the commentary below, Francine Cournos, M.D., and Stephanie Le Melle, M.D., discuss the article on page 989, reprinted from the July 1981 issue of Hospital and Community Psychiatry. That article described a new group of chronic patients, young adults with poor social functioning who were draining the resources of publicsector programs. Drs. Cournos and Le Melle place the emergence of this patient group within a larger context of shifts in funding streams for social welfare programs and a lack of resources for communitybased care. They describe studies published in this journal in the 1980s that examined many issues related to the treatment of young adult chronic patients-homelessness, outpatient commitment, and comorbid substance abuse-and they call on mental health professionals to advocate for more resources to improve patient care. (Psychiatric Services 996-1000, 2000)

I n 1981 a seminal paper by Pepper, Kirshner, and Ryglewicz (1) brought attention to a new group of young adult chronic patients who cycled in and out of mental health programs, alternately demanding and refusing services. They often got into trouble with their use of alcohol and drugs and intermittently entered the criminal justice system. They were unwilling or unable to think of themselves as mental patients.

This new group did not have the same passivity or dependence on psychiatric institutions as those who had previously experienced long-term institutional care (2). On

Dr. Cournos is director and Dr. Le Melle is assistant director of the Washington Heights Community Service at the New York State Psychiatric Institute, 1051 Riverside Drive, Unit 112, New York, New York 10032. the contrary, they tended to be superficially independent, moving from program to program, inpatient setting to outpatient setting, and place to place. They became the "revolving-door" patients who frustrated family, friends, and psychiatric caregivers (3). And they were now presenting for treatment at community mental health centers (CMHCs), which had not been set up to deal with their problems.

Each of the themes Pepper and his colleagues drew from their observations in New York State would come to dominate our discourse about patients throughout the country whom our system was failing. Mental health practitioners and the press would come to focus on the mental health system's decision to carry out a poorly conceptualized policy of deinstitutionalization as the explanation for the emergence of this new population of difficult patients and the growing problem of homelessness. Yet in retrospect the picture is much more complex and confusing.

Previous articles in this historical series have detailed many of the critical events that shaped the mental health system in the second half of the 20th century. This paper looks at why the needs of young adult chronic patients overwhelmed the mental health service system by examining the forces our field can minimally influence-social welfare and health care benefits, housing markets, and the larger system of values and legal decisions in which we operate. We believe that although it is important for us to be self-critical, we cannot solve the problem of providing adequate care to patients with severe mental illness until we see ourselves as advocates for the resources we need to practice medicine properly rather than as professionals who intentionally deprive our patients of needed services.

\section{Financing services and deinstitutionalization}

Every system of care we have ever created for people with severe mental illness has had its limitations, not only because we cannot cure these diseases but also because each new system develops in the context of social and economic upheavals over which mental health professionals have little influence. Each reformist surge leaves a "lasting residue of pessimism, retrenchment, and neglect" (4).

Many factors contributed to deinstitutionalization. Of these, only one involved a clinical advance: the introduction of antipsychotic drugs (5). Other factors included an 
increasing societal bias against the use of large, traditional institutions (6) as well as a number of important legal decisions concerning the rights of patients (7). However, the evidence suggests that the most important factor was the opportunity of state governments to shift patients from large hospitals, where care was paid for by states, to alternative care, where newly expanded federal entitlement programs would cover much of the cost (8).

The care of people with chronic mental illness relies heavily on funding streams that are contained within social welfare programs designed for all poor and disabled people and therefore not under the control of mental health agencies. In the second half of the 20th century, the available funding streams included welfare entitlements, Social Security disability payments, Medicare, Medicaid, food stamps, and housing assistance programs, none of which were designed for mentally ill people. Deinstitutionalization occurred as mental health systems shuffled and shifted to respond to funding changes. It was perhaps not until the creation of managed care that mental health practitioners could no longer deny the painful limits of their own authority (9). The view that the mental health care field created deinstitutionalization and the many ills that followed provides a good example of our naïveté.

The term deinstitutionalization was inaccurate, since the use of institutional care was in no way diminished. Rather, there was a depopulation of state hospitals while the number of people living in other types of institutions grew. According to the U.S. census, 1.05 percent of the population resided in institutions in 1950, 1960, and 1970, and the percentage rose slightly to 1.1 percent in 1980 (10).

But the kinds of institutions differed, and they included an increasing number of new settings for the elderly population. In 1950 some 40 percent of institutionalized people were in mental hospitals, and 20 percent were in homes for the aged and dependent. By 1980 only 10 percent of the institutionalized were in mental hospitals, and more than 50 percent were in homes for the aged and dependent (10). States were able to reduce their costs by using federal money, on a matching basis, to pay for nursing home care (11). Elderly state hospital patients either died or were transinstitutionalized, and new admissions of the elderly often were to nursing homes, which grew into a large new industry as state hospitals shrank. By the start of the 1980s some 750,000 mentally disabled elderly people were in nursing homes; 400,000 of them had "senility without psychosis," and 350,000 had other mental disorders (12).

Deinstitutionalized middle-aged state hospital patients, who were accustomed to treatment compliance after years of institutional care, could be discharged to single-roomoccupancy hotels and other forms of cheap and substandard housing. Although these settings often lacked needed services, they at least provided shelter, and most discharged patients preferred living outside the hospital even if the supports were meager (13). It was hoped that younger patients who had never experienced long-term institutional care could anticipate a brighter future in the community (14).
By 1980 the census of the state hospital system had dropped by 76 percent, from its 1955 peak of 559,000 patients to just 132,000 (15). Hospital care remained important, but it shifted to the use of briefer admissions that increasingly occurred on psychiatric units in general hospitals (14). This trend was also supported by economic forces - in this case by changes in both private and federally funded health care benefits (9). Between 1969 and 1982 the number of acute psychiatric admissions increased 116 percent, from 9.76 million to 21.12 million (15).

\section{Community care and its problems}

With hospitalization limited to brief stays, the care of severely ill patients increasingly shifted to the community. However, as has often been stated, adequate services did not follow the patients. For example, Lipton and colleagues (16) noted that from 1978 to 1980, the New York State Office of Mental Health spent $\$ 4.5$ billion on state hospitals but only $\$ 540$ million on community-based services, despite a 70 percent decline in the state hospital population since 1965 from 85,000 to 25,000 beds.

Yet this shift was also a complicated issue, for now patients were hospitalized for active treatment that had grown much more expensive and had to be conducted with much higher standards than custodial care, greatly increasing the operating costs of the state hospital beds that remained (17). And so we found ourselves caught in a paradox: on the one hand, we complained that there were too few hospital beds for those who needed this level of supervision, but on the other hand, we bemoaned spending too much money on the hospital care that we had.

Lack of sufficient funding for comprehensive mental health care was not the only economic issue the mental health system faced. Still another set of forces would cause a growing number of patients to shift from unsupervised living in run-down housing to homelessness. The mid1970s and early 1980s would see the gentrification of inner-city neighborhoods with the loss of almost all singleroom-occupancy housing, reduced public money for new low-cost housing, the federal government's attempt to remove people with mental illness from the disability benefits programs of the Social Security Administration, and the reduced value of other entitlements that did not keep pace with inflation (11). People with mental illness competed for shrinking benefits and inexpensive housing with others who were poor and disadvantaged. It is estimated that between 1980 and 1988 the number of single adults living in shelters rose from 35,000 to 115,000 and the number of single adults living in public places rose from 86,000 to 209,000 (18). Estimates varied, but probably one-quarter of these people had severe mental illness (18).

Still another important institutional shift was a large expansion of the prison population, a trend that grew out of government efforts to control illicit drug use by pressing for higher arrest rates and longer prison sentences. Young chronic patients who engaged in such drug use were alternately handled by brief hospitalization or through the criminal justice system. And so jail became the asylum for 
an increasing number of people with dual diagnoses (19).

The mental health system was not lacking in ideas about how to provide innovative community-based care, but rather in the resources to carry them out. Expanded outpatient services, emergency services, home care, day treatment, rehabilitation initiatives, and group and family therapy programs were all under way by the 1950s when the depopulation of state hospitals began $(14,15)$. These new programs were thought to lead to "increasing respect for the dignity of each patient" (14). Considering the poor conditions in many state hospitals at the time of deinstitutionalization (20), these changes undoubtedly benefited many people. But funding for new services was insufficient even for patients who wanted them. Given this context, the greatest challenge would be how to "address the issue of people who are not in treatment, who resist treatment, and who become marginalized and destitute" (14).

\section{The mental health system}

\section{was not lacking in ideas} about how to provide innovative community-based care, but rather in the resources to carry them out.

Perhaps the best example of mental health leadership falling short was in the wake of the 1963 passage of the Mental Retardation Facilities and Community Mental Health Centers Construction Act. This legislation provided federal funds to build CMHCs, and these funds were increased in 1975 (17). The CMHC programs that were developed were run by activist community leaders and mental health professionals who put most of their efforts into psychotherapy, liaisons with the community, and other rehabilitation models geared toward higher-functioning patients (11).

For the most part, CMHCs did not address the more traditional mental health services, which were geared toward the severe and persistently mentally ill population. But even if they had been more interested in serving chronic patients, the money appropriated to CMHCs was limited. So, for example, all federal payments received by CMHCs between 1963 and 1981 were less than the estimated payments for Supplemental Security Income and Social Security Disability Insurance received directly by the mentally disabled during 1981 alone (10).

A growing awareness of the unmet needs of severely ill patients led to the development in the late 1970s of com- munity support programs. However, these programs, initiated by the National Institute of Mental Health, often served an older population, especially in New York State, where the median age of community support program patients was 56 years $(21,22)$. Young chronic patients remained the group with the fewest services tailored to their needs.

\section{American psychiatry from 1981 to 1985}

The evolving concept of the young chronic patient was reflected in many articles published in Hospital and Community Psychiatry from 1981 through 1985. Attempts were made to define subgroups of this population by symptoms (23) and by demographic characteristics (24). Others tried to look at the clinical needs of this population (3,25-28). In general these studies found that although this group had a wide variety of diagnoses, they had some common problems and needs.

Most visible was the need for stable housing as homelessness became an ever more obvious problem. Referring to the homeless as the "walking wounded," Lipton and colleagues (16) cited the economic factors that contributed to the homelessness problem: the slumping national economy, inflation and unemployment, cuts in federal and state support, lack of low-cost housing resulting from redevelopment of inner-city areas, and the discharge of large numbers of psychiatric patients to communities over the past 20 years without adequate community resources.

Some housing programs for mentally ill persons existed, and the concept of supportive community-based housing evolved with the acknowledgment that chronic patients were heterogeneous and functioned at different levels, thus requiring an array of housing options offering different levels of supervision (29). However, residential programs were in short supply and were not suitable for many of the young adult chronic patients whose behavior could be disruptive and who were loath to accept the loss of personal freedom. (28)

A concern about the link between homelessness and treatment refusal led to much debate about legal and ethical issues surrounding the right to refuse treatment (30-32). Yet there were many treatment-seeking patients as well. A connection was made between homelessness and the increase in acute hospitalizations as self-referred patients arrived at hospitals "searching for a safe and secure environment" (33). In one study, Arce and colleagues (34) observed that 86 percent of homeless mentally ill people agreed to take medications when treatment was offered, suggesting that many might in fact want help if it was presented in an acceptable way. This situation became another controversy: were mentally ill homeless people refusing care, or was appropriate treatment for this population largely unavailable? Throughout the debate, young chronic patients remained ever visible in decompensated states on the streets.

In hopes of hospitalizing those who were most obviously ill, the psychiatric community began to reconsider the criteria for court-mandated hospitalization (35-38). Treffert 
(30) noted that because of the strict standards of civil commitment laws, "obviously ill psychiatric patients are left to deteriorate in order to qualify for treatment, or, just as wrongly, to be treated in jails or prisons, or, just as cruelly, to wander the streets untreated and suffering."

Several articles dealing with outpatient commitment to treatment also appeared. It seemed that this approach could be a compromise between forced hospitalization and treatment refusal, allowing patients to remain in the least restrictive environment. In a 1984 study looking at the use of outpatient commitment in North Carolina, Miller and Fiddleman (39) found that only 3.1 to 4.7 percent of all commitments were outpatient commitments. Nationwide the results were similar: outpatient commitment constituted less than 5 percent of all commitments (40). Miller and Fiddleman (39) attributed these small figures to lack of knowledge of existing statutes and to the reluctance of CMHCs to treat unwilling patients. They concluded, "Society seems disinclined to abandon involuntary treatment for its mentally ill, and many patients seem equally disinclined to seek treatment voluntarily, even as an alternative to involuntary inpatient commitment."

Patients continued to cycle in and out of short-term hospital care (26), and we struggled with poor treatment compliance and failure of community programs to effectively engage patients. Lamb (28) highlighted the innate lack of insight associated with chronic psychotic illness, "the natural rebelliousness of youth," and the newly emerging substance abuse problem that contributed to recidivism. "A large proportion of new chronic patients," he wrote, "tend to deny a need for mental health treatment. . . . Instead many medicate themselves with street drugs; thus they also gain admittance to the drug subculture, where they can find acceptance despite their lack of status in the conventional sense." Many saw "ego deficits" as an important part of the population's problems, and Schwartz and Goldfinger (25) noted that "there is a lack of fit between this group's characteristic style of interaction and existing communitybased programs."

Treatment adherence problems were complicated by the fragmentation of care. The decentralization of services outside of the state hospital setting led to a lack of coordination as various agencies and bureaucracies became involved with these patients in a piecemeal way, thus leading to ineffectual distribution of services (34). Talbott (41) referred to the available services as an "antiquated, unresponsive, scandal-ridden, mental health "nonsystem."”

Efforts were undertaken to reach homeless persons with mental illness. In 1984 Ball and Havassy (42) described a new program called Project HELP: Homeless Emergency Liaison Project. The authors noted the low priority that their target populations accorded the psychiatric and social services offered them by community mental health agencies, instead blaming their inability to avoid hospital readmissions on lack of basic resources for survival such as housing, work, and benefits. The relative contributions of poverty on the one hand and mental illness on the other to the problem of homelessness would remain a much debated issue.

The theme of substance use became increasingly prominent. We were slow to recognize that many of our patients suffered from comorbid substance use disorders, a problem that had occurred less frequently when long-term hospitalization limited patients' access to alcohol and drugs. Schuckit (43) recommended that substance use problems become part of the differential diagnosis of almost all psychiatric patients, noting that "unless therapists consider these diagnoses in every patient, they may be offering inadequate care to one out of five patients they treat." And the first mention of AIDS appearing on a psychiatric inpatient unit was published in 1985 (44), heralding the future spread of this epidemic among people with severe mental illness, especially those who used illicit drugs (45).

For many of the young chronic patients who were unable to engage in available treatment or survive independently in the community, the only reliable source of concern and support was their families, and there much of the burden of care fell. Hatfield (46) noted that "families have become the primary resource for patients, and if the community care experiment is to survive, good collaborative relationships between families and professionals are crucial." This sentiment began to grow with the founding of the National Alliance for the Mentally Ill and other advocacy groups (17), and eventually we began to see the wisdom of joining forces with families to fight for parity, reduce stigma, and fund new research.

\section{Conclusions}

Much has happened since the early 1980s. Outreach and housing programs have expanded to serve homeless people; several models have been developed for the treatment of mentally ill patients with comorbid substance use disorders; community-based programs have assumed more responsibility for treating severe mental illness; new medications have been introduced; and there is a growing emphasis on recovery. However, many of the problems remain: the limited supply of affordable housing; lack of sufficient funding for programs and of a centralized funding mechanism that would promote the integration of care; continuing problems with substance abuse, the spread of HIV, and other health care problems; the large number of mentally ill people in prison; medications that are still only somewhat effective; and problems with adherence.

The young adult chronic patients of the early 1980s are now middle-aged and have been joined by a new cohort of young adult chronic patients. Managed care has taught us the limits of our power. Perhaps we are ready to pursue our goals with a greater political understanding that it is in our domain to develop clinical advances, but not to fund them. We must join with patients and families in the difficult task of advocating for the financial resources that are necessary to create a more humane and comprehensive system to care for the treatment of young people who are stricken by chronic mental illness. 


\section{References}

1. Pepper B, Kirshner MC, Ryglewicz H: The young adult chronic patient: overview of a population. Hospital and Community Psychiatry 32:463-469, 1981

2. Lamb HR: Deinstitutionalization and the homeless mentally ill. Hospital and Community Psychiatry 35:899-907, 1984

3. Bachrach LL: Young adult chronic patients: an analytical review of the literature. Hospital and Community Psychiatry 33:189-197, 1982

4. Morrissey JP, Goldman HH: Cycles of reform in the care of the chronically mentally ill. Hospital and Community Psychiatry 35:785-793, 1984

5. Duval AM, Goldman D: The new drugs (chlorpromazine and reserpine): administrative aspects. Mental Hospitals 7(2):30-34, 1956

6. Goffman E: Asylums: Essays on the Social Situation of Mental Patients and Other Inmates. Garden City, NY, Anchor Books, 1961

7. Appelbaum PS: The Draft Act Governing Hospitalization of the Mentally Ill: its genesis and its legacy. Psychiatric Services 51:190-194, 2000

8. Frank RG: The creation of Medicare and Medicaid: the emergence of insurance and markets for mental health services. Psychiatric Services $51: 465-468,2000$

9. Sharfstein SS: Whatever happened to community mental health? Psychiatric Services 51:616-620, 2000

10. Cournos F: Clinical services for schizophrenia. Psychiatric News, Feb 2, 1990

11. Bloche MG, Cournos F: Mental health policy for the 1990s: tinkering in the interstices. Journal of Health Politics, Policy, and Law $15: 387-411,1990$

12. Goldman HH, Gattozzi AA, Taube CA: Defining and counting the chronically mentally ill. Hospital and Community Psychiatry 32:21-27, 1981

13. Segal SP, Aviram U: The Mentally Ill in Community-Based Sheltered Care: A Study of Community Care and Social Integration. New York, Wiley, 1977

14. Barton WE: Trends in community mental health programs. Hospital and Community Psychiatry 17:253-258, 1966

15. Redick RW, Witkin MJ: State and County Hospitals, United States, 1970-1980 and 1980-1981. Mental Health Statistical Note 165. Rockville, Md, National Institute of Mental Health, 1983

16. Lipton FR, Sabatini A, Katz SE: Down and out in the city: the homeless mentally ill. Hospital and Community Psychiatry 34:817-821, 1983

17. Geller JL: The last half-century of psychiatric services as reflected in Psychiatric Services. Psychiatric Services 51:41-67, 2000

18. Jencks C: The Homeless. Cambridge, Mass, Harvard University Press, 1994

19. Lamb HR: Keeping the mentally ill out of jail. Hospital and Community Psychiatry 35:529, 1984

20. Rothman D: Conscience and Convenience. Boston, Little, Brown, 1980

21. Baker F, Intagliata J: The New York State community support system: a profile of clients. Hospital and Community Psychiatry 35:39-44, 1984

22. Intagliata J, Baker F: A comparative analysis of the young adult chronic patient in New York State's community support system. Hospital and Community Psychiatry 35:45-50, 1984

23. Green RS, Koprowski PF: The chronic patient with a nonpsychotic diagnosis. Hospital and Community Psychiatry 32:479-481, 1981
24. Sheets JL, Prevost JA, Reihman J: Young adult chronic patients: three hypothesized subgroups. Hospital and Community Psychiatry 33:197-203, 1982

25. Schwartz SR, Goldfinger SM: The new chronic patient: clinical characteristics of an emerging subgroup. Hospital and Community Psychiatry $32: 471-474,1981$

26. Caton CL: The new chronic patient and the system of community care. Hospital and Community Psychiatry 32:475-478, 1981

27. Tessler RC, Manderscheid RW: Factors affecting adjustment to community living. Hospital and Community Psychiatry 33:203-207, 1982

28. Lamb HR: Young adult chronic patients: the new drifters. Hospital and Community Psychiatry 33:465-468, 1982

29. Campanelli PC, Lieberman HJ, Trujillo M: Creating residential alternatives for the chronically mentally ill. Hospital and Community Psychiatry $34: 166-167,1983$

30. Treffert DA: The obviously ill patient in need of treatment: a fourth standard for civil commitment. Hospital and Community Psychiatry 36:259-264, 1985

31. Appelbaum PS: AE \& RR: Utah's compromise on the right to refuse treatment. Hospital and Community Psychiatry 32:167-168, 1981

32. Byrne G: Conference report: Wyatt v Stickney: retrospect and prospect. Hospital and Community Psychiatry 32:123-126, 1981

33. Appleby L, Desai PN: Documenting the relationship between homelessness and psychiatric hospitalization. Hospital and Community Psychiatry 36:732-737, 1985

34. Arce AA, Tadlock M, Vergare MJ, et al: The psychiatric profile of street people admitted to an emergency shelter. Hospital and Community Psychiatry 34:812-817, 1983

35. Stromberg CD, Stone AA: A model state law on civil commitment of the mentally ill. Harvard Journal on Legislation 20:275-396, 1983

36. Appelbaum PS: Special section on APA's model commitment law: an introduction. Hospital and Community Psychiatry 36:966-967, 1985

37. Zusman J: APA's model commitment law and the need for better mental health services. Hospital and Community Psychiatry 36:978-980, 1985

38. Durham ML, Carr HD, Pierce GL: Police involvement and influence in involuntary civil commitment. Hospital and Community Psychiatry 35:580-584, 1984

39. Miller RD, Fiddleman PB: Outpatient commitment: treatment in the least restrictive environment? Hospital and Community Psychiatry 35:147-151, 1984

40. Miller RD: Commitment to outpatient treatment: a national survey. Hospital and Community Psychiatry 36:265-267, 1985

41. Talbott JA: The fate of the public psychiatric system. Hospital and Community Psychiatry 36:46-50, 1985

42. Ball FL, Havassy BE: A survey of the problems and needs of homeless consumers of acute psychiatric services. Hospital and Community Psychiatry 35:917-921, 1984

43. Schuckit MA: Alcoholism and other psychiatric disorders. Hospital and Community Psychiatry 34:1022-1027, 1983

44. Polan HJ, Hellerstein D, Amchin J: Impact of AIDS-related cases on an inpatient therapeutic milieu. Hospital and Community Psychiatry 36:173-176, 1985

45. Cournos F, McKinnon K: HIV seroprevalence among people with severe mental illness in the United States: a critical review. Clinical Psychology Review 17:259-269, 1997

46. Hatfield AB: Therapists and families: worlds apart. Hospital and Community Psychiatry 33:513, 1982 